\title{
Amy Howard, More Than Shelter: Activism and Community in San Francisco Public Housing (Minneapolis: University of Minnesota Press, 2014). 308 pp. Paperback $\$ 27.50$.
}

\section{In More Than Shelter: Activism and Community in San Francisco Public Housing, Amy} Howard demonstrates how San Francisco Housing Authority (SFHA) policies were aimed at perpetuating racial and class stereotypes associated with public housing. While Howard deftly navigates San Francisco's public housing policies and their flaws, she also reveals through her personal interviews the resilience of communities and their pride of place. By delving into case studies of three housing units, Valencia Gardens, Ping Yuen, and North Beach Place, Howard shows how residents worked together to create social cohesion in order to collectively challenge the San Francisco Housing Authority's policies during the late 1980s and 1990s.

Howard's work is laid out in five chapters. The first chapter provides a history of federal housing policy in the United States, which sought to strengthen "democracy through public housing" by molding the residents into ideal citizens.

(1) The ideal citizen aspired to upward mobility and was compliant, rule-following, orderly, and lived in racially and ethnically uniform establishments. Howard then narrows her focus on the history of the SFHA. The middle three chapters each cover a specific housing unit. Collectively, they illustrate the ramifications of SFHA policy decisions and how they fed into stereotypes that public housing was full of drug lords, crime, and violence in the housing units. The fifth and concluding chapter summarizes the impact of funding decisions on the sense of community in each of the housing units.

The case studies of Valencia Gardens, Ping Yuen and North Beach Place each serve as a lens through which to examine a different facet of SFHA policy and how residents of the unit practiced what Howard calls "affective activism" in which their "activism focused on intentional relationships and community building to fortify participants in the face of shared challenges." (50) Chapter two, "The Contested Mission of Valencia Gardens," illustrates the class stereotypes associated with public housing. The complex received several Bufano sculptures, which were seen as integral to the way the community positioned itself in space. Several of the interviewees remembered the sculptures as forming an integral part of their childhood in the games they played around them. However, the city wanted to relocate them to a more middle class area of the city in order to capitalize on their tourist draw. The residents of Valencia Gardens fought the removal of the sculptures, and once the reconstruction of the complex was complete most of the statues were returned.

Chapter three, “'Peace and Prosperity Dwell among Virtuous Neighbours' Chinatown's Public Housing," sheds a different light on SFHA policy by illustrating 
racial stereotypes associated with public housing at Ping Yuen. Unlike the more culturally diverse Valencia Gardens and North Beach Place, Chinese-Americans almost exclusively populated the housing development. Rather than trying to move tourists away from public housing, as the relocation of the Bufanos demonstrated in Valencia Gardens, the SFHA sought to capitalize on the Asian features of San Francisco's Chinatown by creating an exterior aesthetic of Ping Yuen to resemble a western conception of Asian architecture. The residents of this complex fought hard to maintain their racial segregation as a predominately Chinese public housing unit, but at the same time successfully worked together to ensure "a decent and safe living environment" by participating in rent strikes as a way to raise their voices to ensure they were not marginalized because of their Chinese heritage. (132)

Chapter four, "The Best Project in Town' North Beach Place," illustrates the challenges with cross-cultural communication in a racially integrated complex. Residents of the complex, located in a racially diverse neighbourhood, drew together to advocate for their housing unit in the face of rising crime and a lack of funding for building improvements. However, it was the "threat of redevelopment and dislocation from the vibrant North Beach neighbourhood," that ultimately led to the "unprecedented collaboration between racial and ethnic groups." (151) The SFHA sought to relocate the public housing unit outside of the city and construct a hotel in its place in order to capitalize on the increased tourist revenues because of the redevelopment of Pier 42 as a tourist destination.

The strength of More Than Shelter rests in the explication of the sense of community created in each of the public housing complexes as a direct challenge to oppressive housing policies, and their desire to preserve and protect their homes. Throughout her discussion of Valencia Gardens, Ping Yuen and North Beach Place, she illustrates how pride of place in their living spaces was demonstrated in how they decorated their dwellings, raised their children, and created a community of care. The intersection of tourism and public housing woven throughout Howard's work, sheds light on ways policies encouraged the expansion of the tourist economy at the expense of those in a lower income bracket; however, inhabitants crossed cultural and language barriers and worked with the surrounding community in order to challenge the SFHA to provide upgrades and improvements. Howard provides many examples of how "low-income tenants in all three communities challenged the popular reductive stereotype of the 'projects' as crime-ridden, anti-public wastelands populated by lazy freeloaders." (203) While the Hope IV funding was granted, by the federal government, with the aim of improving the living situations of those in public housing, the opposite occurred. The shelter was improved, but at the expense of established community ties because of the length of time it took to complete the renovations. As both the renovation of Valencia Gardens and North Beach Place illustrate, only a small minority of the relocated residents moved back in once the complex was complete. Howard's work sheds an important light on the impact of public housing policies on communities. Housing is more than shelter; it is a 
place for residents to raise families, share their culture, and, as this book reveals, find a voice to overcome challenges faced living in federal housing.

Jennifer Chutter

Simon Fraser University

\section{Joanna Dreby, Everyday Illegal: When Policies Undermine Immigrant Families (Oakland, CA: University of California Press, 2015). 287 pp. \$29.95 Paper- back.}

Everyday Illegal: When Policies Undermine Immigrant Families is a sequel to Joanna Dreby's 2010 book Divided by Borders: Mexican Migrants and their Children. In this new ethnographic contribution, Dreby conducted interviews with 110 children and 91 parents in New Jersey and Ohio to study the complex relational dynamics that develop within unauthorized Mexican immigrant communities. From the outset, Dreby importantly clarifies that this project does not represent all Mexicans living within both locations of interest and focuses on heteronormative family structures. Everyday Illegal demonstrates how, under the enforcement of restrictive US immigration law during the Obama administration, familial and peer dynamics are strained not only juridicially but also socially for immigrant families. It elucidates various interpersonal effects constituted and exacerbated by punitive US immigration policy, all of which may be overlooked through a merely legal understanding of unauthorized immigrant livelihood.

The culture of fear produced by punitive immigration policy is, Dreby argues, a serious public health concern. The threat of deportation has material effects on the anxiety levels of parents, especially those of unauthorized women who are susceptible to becoming what she terms suddenly single mothers. Illegality exposes mothers to ataques de nervios (anxiety attacks), for instance, which may also involve episodes of self-harm, as it does for one of Dreby's interviewees. Additionally, some migrant children who were interviewed described having regularly faced educational barriers, lack of access to adequate healthcare, and food insecurity. The recent rise of these severe social effects in the US are correlated, for Dreby as well as for many other scholars, to the post-9/11 creation and continuing expansion of the Department of Homeland Security's enforcement procedures.

Dreby's study also shows how legal-status differences bolster daily experiences of gender inequality for women. These dynamics of illegality augment the abusive social conditions within which many unauthorized women already find themselves, especially with the rapid emergence of mixed-status families in the US (mixed-status families are those consisting of authorized and unauthorized members). As Dreby's field work as well as personal experiences with mixed-status familial life suggest, legalization is closely linked for some immigrant men to patriarchal conceptions of masculinity, where both legal status and a lack thereof 